University of Nebraska - Lincoln

DigitalCommons@University of Nebraska - Lincoln

Faculty Publications from the Department of Electrical \& Computer Engineering, Department Electrical and Computer Engineering

$5-1-2002$

\title{
Oxygen plasma effects on optical properties of ZnSe films
}

Li Yan

University of Nebraska-Lincoln

John A. Woollam

University of Nebraska-Lincoln, jwoollam1@unl.edu

Eva Franke

Institut für Oberflächenmodifizierung Leipzig, efranke3@unl.edu

Follow this and additional works at: https://digitalcommons.unl.edu/electricalengineeringfacpub

Part of the Electrical and Computer Engineering Commons

Yan, Li; Woollam, John A.; and Franke, Eva, "Oxygen plasma effects on optical properties of ZnSe films" (2002). Faculty Publications from the Department of Electrical and Computer Engineering. 9.

https://digitalcommons.unl.edu/electricalengineeringfacpub/9

This Article is brought to you for free and open access by the Electrical \& Computer Engineering, Department of at DigitalCommons@University of Nebraska - Lincoln. It has been accepted for inclusion in Faculty Publications from the Department of Electrical and Computer Engineering by an authorized administrator of DigitalCommons@University of Nebraska - Lincoln. 


\title{
Oxygen plasma effects on optical properties of ZnSe films
}

\author{
Li Yan ${ }^{\text {a) }}$ and John A. Woollam \\ Center for Microelectronic and Optical Materials Research and Department of Electrical Engineering, \\ University of Nebraska-Lincoln, Lincoln, Nebraska 68588-0511 \\ Eva Franke \\ Institut für Oberfächenmodifizierung Leipzig, 04318 Leipzig, Germany
}

(Received 1 March 2001; accepted 29 January 2002)

\begin{abstract}
Zinc selenide is an infrared transparent semiconductor material being considered for use in space as an infrared optical coating. In this work, zinc selenide thin films of different thicknesses were exposed to an electron cyclotron resonance generated oxygen plasma, often used to "simulate" the low earth orbital environment. The maximum fluence used in our experiments was equivalent to $\sim 16$ years in the low earth orbital environment. ZnSe thin film optical constants (both before and after oxygen plasma exposure) were determined using variable angle spectroscopic ellipsometry from the vacuum ultraviolet at $146 \mathrm{~nm}$ through the middle infrared to $40 \mu \mathrm{m}$. A parametric dispersion model (Herzinger-Johs) was successfully used to fit the optical data over the entire range from ultraviolet to infrared. Comparing the pre- and post-oxygen plasma exposure data, few changes were observed in the middle infrared region, while drastic changes were seen in the vacuum ultraviolet through visible to near infrared $(0.73-8.5 \mathrm{eV})$. This suggests that chemical changes upon plasma exposure, including oxidation, are found mainly in a thin layer near the surface. As the proposed application is for infrared coatings, and few infrared changes were seen under conditions roughly equivalent to 16 years in low earth orbit, $\mathrm{ZnSe}$ may indeed be useful for space infrared applications. Performance simulations of $\mathrm{ZnSe}$ coated infrared-operating electrochromic thermal-control surfaces confirm this conclusion. (C) 2002 American Vacuum Society.
\end{abstract}

[DOI: $10.1116 / 1.1463085]$

\section{INTRODUCTION}

Wide-gap II-VI semiconductors have received considerable attention over the last decade because of potential applications in various optoelectronic devices. ${ }^{1-4}$ Among them, zinc selenide $(\mathrm{ZnSe})$ is especially attractive due to its direct, wide band gap (2.7 eV at room temperature), making it suitable for blue light emitting optical devices. In addition, $\mathrm{ZnSe}$ is of interest as an infrared coating material owing to its broad spectral band of high transmission from 600 to about $20000 \mathrm{~nm} .^{5}$ Knowledge of the optical response over a wide spectral range is critical for optical applications of $\mathrm{ZnSe}$, and other II-VI compounds as well. In the past, many experiments have been performed to measure the reflection, transmission, band-gap energies, and refractive index of ZnSe $^{6-10}$ To determine the optical constants ( $n$ and $k$ ) from reflectance data alone, Kramers-Kronig (KK) analysis is necessary. The reflectance technique requires measurements over a wide range of photon energies to get accurate results, and this may partially explain discrepancies between reported results. Also, different film deposition techniques and deposition conditions could produce differences in optical constants. Recently, several studies have employed spectroscopic ellipsometry (SE) to determine the optical dielectric functions of $\mathrm{ZnSe}$ films, without the need for $\mathrm{KK}$ analysis. $^{11-18}$ These studies cover measurements over the spectral range $(1.5-6 \mathrm{eV})$ and include both single- and polycrystalline samples. Meanwhile, overlayer effects were mini-

${ }^{\text {a)} E l e c t r o n i c ~ m a i l: ~ y a n l i 75 @ y a h o o . c o m ~}$ mized by either physical removal through chemical etching or by mathematical removal within an optical model. Overlayers include both native oxide and surface roughness. Despite the differences in their physical nature, the effect of either type of overlayer on the apparent dielectric function of the film is similar. ${ }^{16}$ In the present study, we assumed overlayer effects to be adequately represented by a roughness layer in the regression analysis. This simplifies the analysis by using only one overlayer parameter in the optical model. With the high sensitivity of ellipsometry to surface overlayers, the final as-determined optical constants are considered to be representative of $\mathrm{ZnSe}$ films with minimal overlayers.

Material degradation due to atomic oxygen (AO) chemical reaction is a very important long-term issue for spacecraft orbiting in low earth orbit (LEO), ${ }^{19-23}$ where the residual atmosphere is composed predominantly of oxygen atoms $(80 \%)$ and nitrogen atoms and molecules $(20 \%))^{24,25}$ In low earth orbit, AO is generated by photodissociation of diatomic oxygen under ultraviolet (UV) radiation from the sun and exists where the mean free path of oxygen atoms is large enough that recombination has low probability. ${ }^{25-28}$ The AO density in LEO is not particularly high and depends strongly on solar activity and position. However, because of the high orbital velocity (approximately $8 \mathrm{~km} / \mathrm{s}$ at Shuttle altitude), the flux is quite high, of the order of $10^{15}$ atoms $/ \mathrm{cm}^{2} \mathrm{~s} .{ }^{29}$ The $\mathrm{AO}$ in LEO environment causes deleterious erosion, contamination, and oxidation problems for spacecraft materials. ${ }^{19-23,26-28,30,31}$

An infrared (IR)-active electrochromic thin film device 


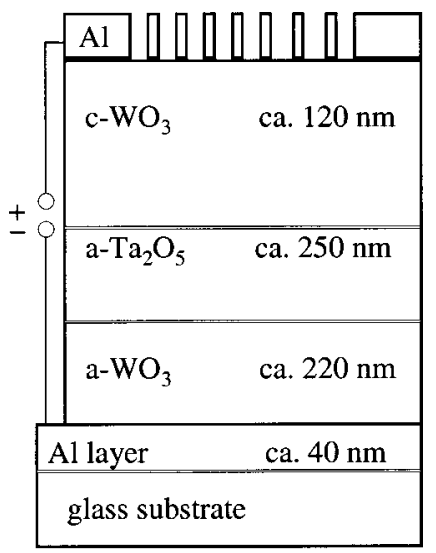

FIG. 1. Layer structure of the all-solid-state electrochromic devices for thermal emittance modulation in the spectral range from 2 to $35 \mu \mathrm{m}$.

was recently developed that operates over the spectral range from 2 to $35 \mu \mathrm{m}^{32-34}$ The design of this electrochromic emissivity modulation device is shown in Fig. $1 .^{34}$ This is potentially useful for thermal control of spacecraft operating at and just above room temperature (300-350 K). However, there is a serious problem that needs to be solved before electrochromics can be used in space: the optical properties of $\mathrm{WO}_{3}$, a major material proposed for use in electrochromic devices, change significantly after exposure to AO. To protect infrared devices from AO erosion in low earth orbit, an infrared antireflection coating would provide enhanced switching performance as well as protection from AO. Among the candidate materials is zinc selenide.

In this article we present the optical constants of thin, polycrystalline $\mathrm{ZnSe}$ at room temperature over a very wide spectral range $(146 \mathrm{~nm}-40 \mu \mathrm{m})$, before and after oxygen plasma exposure, using variable angle spectroscopic ellipsometry $\left(\mathrm{VASE}^{\circledR}\right) .{ }^{35,36}$ Excellent fits between measured and modeled data were obtained. Six critical point structures were observed (for unexposed $\mathrm{ZnSe}$ samples), corresponding to $E_{0}, E_{0}+\Delta E_{0}, E_{1}, E_{1}+\Delta E_{1} E_{2}$, and $E_{0}^{\prime}$, with the latter two being reported experimentally for the first time. The following sections describe film preparation, ellipsometric measurements, and the Herzinger-Johs parametric model, along with data fits. To further investigate chemical changes from oxygen plasma radiation, energy dispersive $\mathrm{x}$-ray spectroscopy (EDX) data were also taken on $\mathrm{ZnSe}$ films both before and after AO exposure. As the proposed application is for infrared antireflection and protective coatings, further simulations of $\mathrm{ZnSe}$ as a protective and antireflection coating for infrared-operating electrochromic thermal-control surfaces were conducted.

\section{EXPERIMENT}

\section{A. Samples}

Thin film ZnSe samples of 100, 200, and $300 \mathrm{~nm}$ thickness (nominal values) were deposited on 2-in.-diameter silicon wafers by Rocky Mountain Instrument Co. using electron-beam evaporation. Typical pressure in the deposi- tion chamber was $(2.0-5.0) \times 10^{-5}$ Torr. The substrates were rotated in planetary motion, with "double" rotation during deposition, to enhance uniformity. X-ray diffraction data indicate a preferred [111] orientation for these polycrystalline, close-packed zinc-blende structure films.

\section{B. Ellipsometery}

Spectroscopic ellipsometry (SE) is a well-known surface sensitive, nondestructive, relatively low-cost optical technique widely used to determine film thickness and optical constants. ${ }^{35-40}$ Reflection ellipsometry measures change in the polarization state of light upon reflection from a sample surface. The measurement is expressed as psi $(\Psi)$ and delta $(\Delta)$, which are related to the Fresnel reflection coefficients by $^{40}$

$$
\rho \equiv \tan (\psi) e^{i \Delta}=R_{p} / R_{s},
$$

where $p$ and $s$ correspond to directions parallel and perpendicular to the plane of incidence, respectively.

Recent developments are towards faster and, often times, in situ measurements, making SE a generally useful method. A distinct advantage of SE over more traditional intensityrelated optical measurements, such as reflectance, is that ellipsometry deals with amplitude ratios and phase changes. ${ }^{40}$ Thus it provides more information from a single measurement than reflectance, and eliminates the necessity for Kramers-Kronig analysis. Moreover, both measured terms $(\Psi$ and $\Delta)$ in ellipsometry relate to a rapidly modulating intensity ratio, which, in turn, makes ellipsometric measurements insensitive to fluctuating light intensity, electronic drift, etc. For these reasons, ellipsometry measurements can be accurate and highly reproducible. ${ }^{40,41}$

It is well known that the optical constants of solids can be described in terms of either complex refractive index $(N$ $=n-i k)$ or (equivalently) the complex dielectric function $\left(\varepsilon=\varepsilon_{1}-i \varepsilon_{2}\right)$. For an optically isotropic bulk material the complex dielectric constant is directly related to the complex reflection ratio $\rho$ by $^{40}$

$$
\frac{\varepsilon}{\varepsilon_{0}}=\sin ^{2} \Phi_{0}\left[1+\left(\frac{1-\rho}{1+\rho}\right)^{2} \tan ^{2} \Phi_{0}\right],
$$

where $\varepsilon_{0}$ refers to the complex dielectric function of the ambient, most commonly air, and $\Phi_{0}$ is the angle of incidence. Strictly speaking, this relation is valid only for a smooth and bulk (nonmultilayered) surface. For a nonideal surface or, more generally, a multilayered structure, the result calculated from ellipsometrically determined complex reflectance ratios [Eq. (2)] is no longer the true dielectric function for a specific layer in the structure. Rather, it is commonly referred to as the pseudodielectric function, $\langle\varepsilon\rangle=\left\langle\varepsilon_{1}\right\rangle$ $+i\left\langle\varepsilon_{2}\right\rangle{ }^{42}$ However, calculating and plotting the pseudodielectric functions are often useful, especially for semiconductor studies. In this article we present $\langle\varepsilon\rangle$ results to show the quality of data fits. Also presented are final optical response $\varepsilon$ for $\mathrm{ZnSe}$ polycrystalline thin films.

In this work measurements were performed over a wide spectral range using three ellipsometers. The first was an 
ultraviolet-visible-near IR (UV-VIS-NIR), monochromatorbased rotating analyzer ellipsometer, covering the spectral range from 0.73 to $6.53 \mathrm{eV}$. The second was an infrared ellipsometer utilizing a rotating polarizer, rotating compensator configuration, with a spectral range of $8000-250 \mathrm{~cm}^{-1}$ $(1.25-40 \mu \mathrm{m})$, where a resolution of $2 \mathrm{~cm}^{-1}$ was chosen. The third was a vacuum ultraviolet (VUV) ellipsometer covering the spectral range 4.5 to $8.5 \mathrm{eV}$. Thus the entire spectral range from $146 \mathrm{~nm}$ to $40 \mu \mathrm{m}$ was covered, with no gaps.

\section{OPTICAL MODELING}

There are many published dielectric function models used for semiconductors in different spectral regions. Some have origins from physics, and others are parametric only. However, few have the flexibility or internal formulation needed to fit optical constants over a broad spectral range. For instance, the Adachi model is best suited for alloy systems in the region below the band gap. ${ }^{43,44}$ Forouhi and Bloomer's dielectric model for semiconductors is Kramers-Kronig (KK) consistent and has a small set of parameters, ${ }^{45}$ but is poor in the band-edge region and below. McGahan ${ }^{46}$ and Jellison $^{47}$ later proposed models that work far better. Oscillator ensembles (harmonic and Lorentz) have been used to describe the above gap behavior of some semiconductors. ${ }^{48,49}$ While these models have been used to fit ellipsometric data, they are unable to describe the direct band-gap spectral regions and require "fictitious" oscillators to fill in absorptions between critical points. Kim and Garland have developed a KK consistent model that adequately describes the semiconductor dielectric function above, below, and through the fundamental direct gap. ${ }^{50,51}$ It can accurately describe the dielectric function and higher order derivatives. However, to determine the required internal parameters a two stage fitting process is needed. Furthermore, there is substantial internal parameter correlation, making it virtually impossible to fit all parameters simultaneously, as is often necessary for optical data analysis.

The Herzinger-Johs parametric optical constant model was developed by Herzinger and Johs $(\mathrm{HJ}),{ }^{52}$ initially for analysis of compound semiconductor films. It has since proven to be of great benefit for analyzing a large variety of optical data for both direct and indirect gap semiconductor materials as well as other materials. ${ }^{53}$ This dispersion model offers many advantages over other dispersion functions: (1) enforces Kramers-Kronig consistency, (2) applicable to virtually any material: dielectrics, semiconductors, metals, etc., (3) uses true Gaussian broadening and allows for complete transparency below the band gap, i.e., $k=0$, (4) $\varepsilon_{2}$ remains positive, and (5) is sensitive enough to capture subtle features which might otherwise be omitted by first principles physics-based models. ${ }^{41}$ However, it has some drawbacks: (1) it has less physical significance, (2) it is somewhat complicated to use, and (3) it may contain parameters correlated to other parameters within the same model. ${ }^{53}$ Considering the strong power and flexibility of the HJ model, these difficulties are minor for the purpose of this work. For this study, the accuracy of the optical constants from a parametric model representation is of prime importance. If parameters from the model have additional physical meaning, that is useful, but secondary. The mathematical details of this model are beyond the scope of this article, but can be found elsewhere. ${ }^{52-54}$ It is worth mentioning, however, that the HJ model is somewhat similar to Kim and Garland's model in the sense that they both use Gaussian broadening and polynomials for the absorption basis functions. However, instead of spanning between critical points, the polynomials are centered around them in the HJ model. In addition, Gaussian broadening is better modeled, yet is KK consistent. ${ }^{54}$ For ellipsometric data analysis over wide spectral range, the ability to correctly model above, below, and through the direct gap is essential, which is why we chose the HJ model. Model parameters can be determined from direct fits of ellipsometric data without the need to fit derivative data. The most physically significant parameters are the energies for critical point transitions, assumed to occur at $\varepsilon_{2}$ maxima.

\section{RESULTS AND DISCUSSION}

\section{A. VUV-UV-VIS-IR ellipsometric data}

Visible ellipsometric data were acquired at three angles of incidence $\left(65^{\circ}, 70^{\circ}\right.$, and $\left.75^{\circ}\right)$ over the spectral range $0.73-$ $6.53 \mathrm{eV}(190-1700 \mathrm{~nm})$ in steps of $0.01 \mathrm{eV}$; vacuum UV data were taken in the spectral range from 4.5 to $8.5 \mathrm{eV}$ at $75^{\circ}$ angle of incidence; and infrared ellipsometric $\Psi$ and $\Delta$ data were acquired at three angles of incidence $\left(65^{\circ}, 70^{\circ}\right.$, and $\left.75^{\circ}\right)$ over the spectral range $200-7000 \mathrm{~cm}^{-1}(0.025-0.868$ $\mathrm{eV}$ ) in steps of $2 \mathrm{~cm}^{-1}$, both before and after oxygen plasma exposure.

The Herzinger-Johs model was employed to fit for the optical constants over the entire spectral range, including the vacuum UV and the middle infrared, along with film thickness. For brevity, all results are presented from the nominally $\sim 100 \mathrm{~nm}$ ZnSe film only. A nearly perfect fit was achieved in the VUV-UV-VIS-NIR before oxygen plasma exposure, as shown for the pseudodielectric functions $\left\langle\varepsilon_{1}\right\rangle$ and $\left\langle\varepsilon_{2}\right\rangle$ in Fig. 2(a), especially in the higher photon energy region. Figure 2(b) shows the same model fits in the middle IR region. The optical model employed is quite straightforward: $\mathrm{Si}$ substrate/native oxide $\left(\mathrm{SiO}_{2}\right) / \mathrm{HJ}$ model layer representing the $\mathrm{ZnSe}$ film/surface roughness. Surface roughness was modeled using a Bruggeman effective medium approximation (EMA) layer, ${ }^{55}$ with a fixed $50 \% \mathrm{HJ}$ material and $50 \%$ air (void) and with thickness as the only regression parameter. The silicon native oxide $\left(\mathrm{SiO}_{2}\right)$ thickness was fixed at 2 $\mathrm{nm}$, a typical value for most native semiconductor oxides. The HJ layer representing $\mathrm{ZnSe}$ was constructed by adding oscillators one by one, starting from the low photon energy end. Details of the entire procedure would be too lengthy to describe here, and we refer the interested reader to Ref. 5254. The HJ parameters for the ZnSe optical constants, $\mathrm{ZnSe}$ thickness, and surface roughness layer thickness were fit simultaneously. It should be noted that only one parametric model set was used to cover the entire spectral range. (The IR data are displayed separately for a better view.) Fits are 

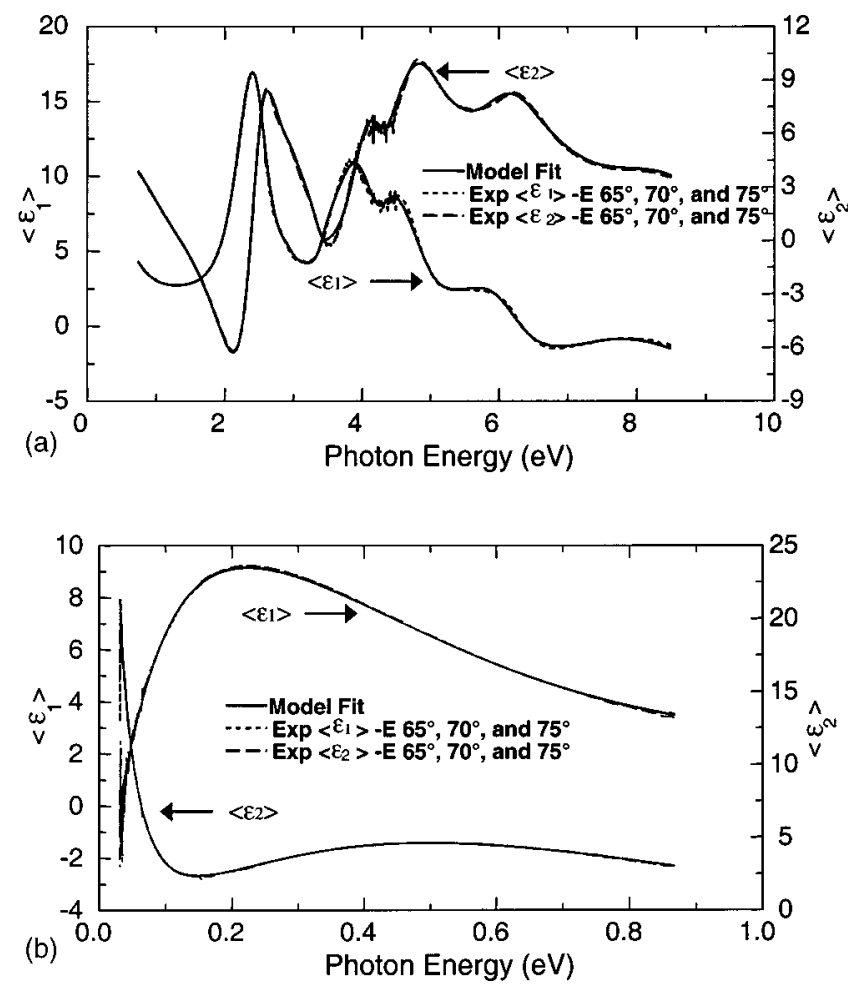

FIG. 2. VUV-UV-VIS-NIR-MIR data (converted to pseudodielectric function) obtained from $\mathrm{ZnSe}$ film (98 nm) on silicon, combined with HerzingerJohs (HJ) model fits, in (a) the VUV-UV-VIS-NIR and (b) the midinfrared (MIR).

nearly perfect over the entire VUV-UV-VIS-IR range with a mean square error (MSE) of only $1.91 .^{40}$ The ZnSe film thickness and surface roughness were determined to be $\sim 98$ and $\sim 3 \mathrm{~nm}$, respectively. Figure 3 shows the true (not pseudo) ZnSe film optical constants before oxygen plasma exposure in terms of $\varepsilon_{1}$ and $\varepsilon_{2}$ determined by analysis of the $\mathrm{SE}$ data using the HJ dispersion model. Six oscillator functions are present, with $\varepsilon_{2}$ peaks corresponding to critical points for $E_{0}, E_{0}+\Delta E_{0}, E_{1}, E_{1}+\Delta E_{1}, E_{2}$, and $E_{0}^{\prime}$ at 2.79 $\pm 0.01,3.54 \pm 0.06,4.2 \pm 0.3,5.0 \pm 0.5,6.29 \pm 0.07$, and 8.1 $\pm 0.3 \mathrm{eV}$, respectively. Here, the final best-fit oscillator center energies are given along with their $90 \%$ confidence limits. The $90 \%$ confidence limits define the range of fit parameter within which there is a $90 \%$ probability of obtaining the true

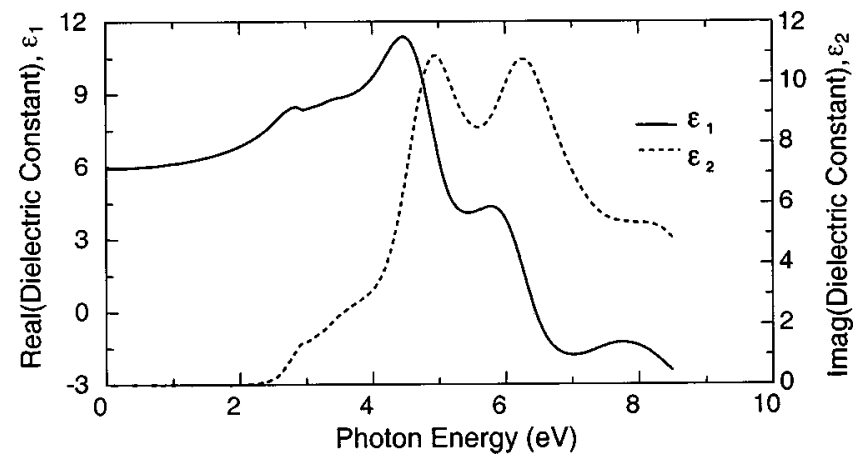

FIG. 3. ZnSe dielectric optical constants $\left(\varepsilon_{1}\right.$ and $\left.\varepsilon_{2}\right)$ in the VUV-UV-VISNIR-MIR.

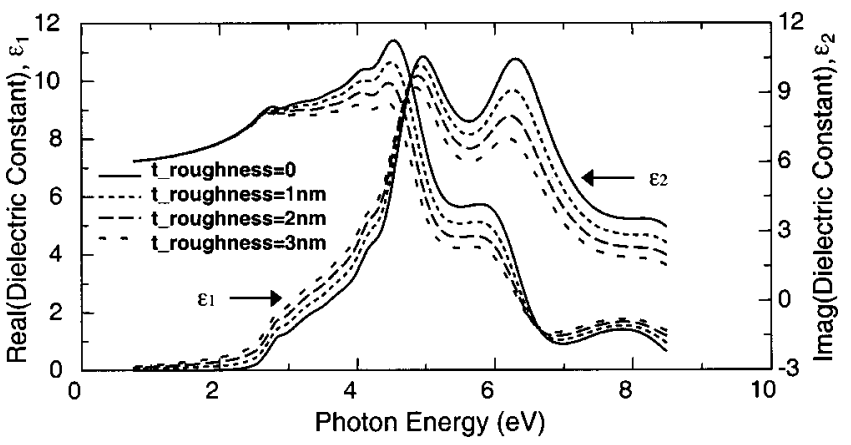

FIG. 4. Simulation of surface roughness effects on $\mathrm{ZnSe}$ film dielectric optical constants $\left(\varepsilon_{1}\right.$ and $\left.\varepsilon_{2}\right)$, assuming the roughness thickness is $0,1,2$, and $3 \mathrm{~nm}$, respectively.

parameter value. ${ }^{40}$ They are a measure of the uncertainty (or error bar) on the final value of a model parameter after a fit. Note that what looks like one peak in the $\varepsilon_{2}$ spectra near 5 $\mathrm{eV}$ actually required two oscillators, one at $4.2 \mathrm{eV}$ and the other at $5.0 \mathrm{eV}$. A wide variety of calculations and experiments have yielded detailed information on the electronic energy-band structure of $\mathrm{ZnSe}$, and some critical point energies (along with corresponding peak positions) have been reported in the literature. ${ }^{56-59}$ The reader is referred to the literature for comparison. To date, however, no critical points in the VUV spectral range (at $\sim 6.29$ and $\sim 8.06 \mathrm{eV}$ ) have been previously observed experimentally.

Roughness and oxide overlayers can significantly affect the final $\varepsilon_{1}$ and $\varepsilon_{2}$ results if not properly accounted for. In this study these effects were accounted for in the fit by assuming only a roughness layer in the model. Data fits show a roughness layer of only $\sim 3 \mathrm{~nm}$ thick. To further justify the validity of our $\mathrm{ZnSe} \varepsilon_{1}$ and $\varepsilon_{2}$ results, simulations of surface overlayer effects (both roughness and oxidation) on film dielectric optical constants, $\varepsilon_{1}$ and $\varepsilon_{2}$, were performed using the analysis software, based on the acquired true $\mathrm{ZnSe}$ optical constants, then adding the overlayers explicitly. Figure 4 shows the variations of calculated $\varepsilon_{1}$ and $\varepsilon_{2}$ due to a change in roughness layer thickness, assuming the roughness to be 0 , 1,2 , and $3 \mathrm{~nm}$ thick, respectively. ${ }^{60}$ The effects of roughness are especially seen in the higher photon energy region, where penetration depths are smaller and the dielectric response of the material is more sensitive to surface properties. Overall, the roughness effects on $\varepsilon_{1}$ and $\varepsilon_{2}$ are substantial, and thus provide the high SE sensitivity and confidence to accurately remove surface roughness layer effects within the optical model.

Likewise, a simulation was made of native oxide effects on the film dielectric optical constants, as illustrated in Fig. 5. Here, $\mathrm{ZnO}$ was assumed to be the only native oxide present, with thicknesses of $0,1,2$, and $3 \mathrm{~nm}$, respectively. Due to the limited spectral range of available $\mathrm{ZnO}$ optical constants, simulation was made for photon energies up to $\sim 3.5 \mathrm{eV}$ only. However, the changes in $\varepsilon_{1}$ and $\varepsilon_{2}$ are similar to results shown in Fig. 4, which verifies the comment made previously that the roughness and native oxides effects on the dielectric functions are similar, and can be safely mod- 


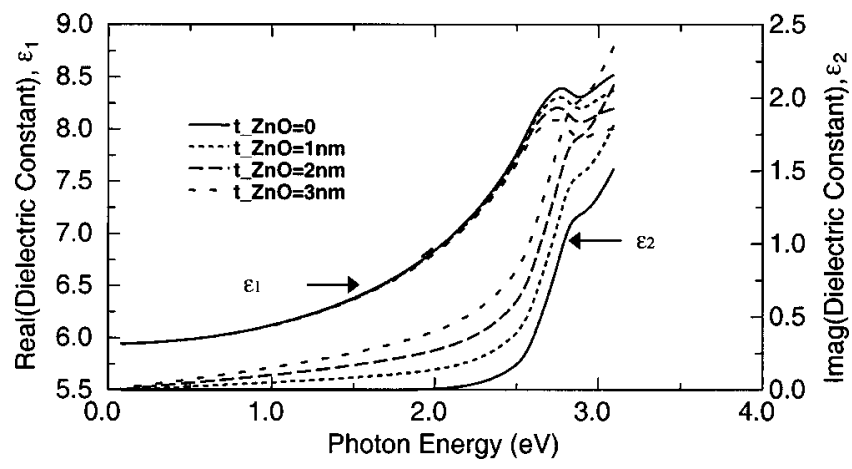

FIG. 5. Simulation of native oxides effects on $\mathrm{ZnSe}$ film dielectric optical constants $\left(\varepsilon_{1}\right.$ and $\left.\varepsilon_{2}\right)$, assuming the oxide is $\mathrm{ZnO}$ only and its thickness is 0 , 1,2 , and $3 \mathrm{~nm}$, respectively.

eled as a roughness layer alone. For the proposed space thermal control coating applications, the most important spectral range is from 2 to $35 \mu \mathrm{m}$, where the overlayer effects on film optical constants appear to be nearly negligible, as shown in Figs. 4 and 5.

Next, the same samples were exposed to oxygen plasma for 8,14 , and $20 \mathrm{~h}$, sequentially, with a $2 \mathrm{sccm}$ oxygen flux flow and $60 \mathrm{~W}$ power supplied to the electron cyclotron resonance (ECR) plasma. Drastic changes in the pseudodielectric functions $\left\langle\varepsilon_{1}\right\rangle$ and $\left\langle\varepsilon_{2}\right\rangle$ were observed in the VUV-UV-VISNIR spectral range, as illustrated in Figs. 6(a) and 6(b), re-
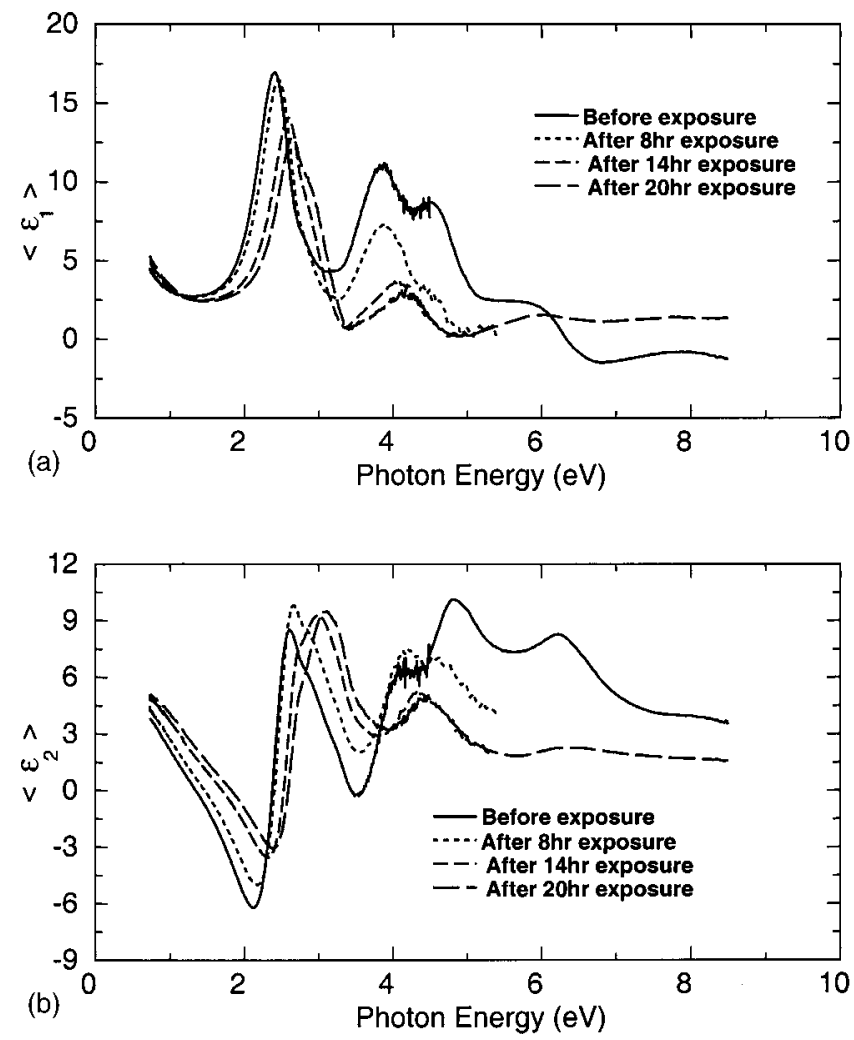

FIG. 6. Comparison of spectroscopic ellipsometric raw data obtained from a previous $\mathrm{ZnSe}$ sample in Fig. 1 before and after 8, 14, and $20 \mathrm{~h}$ of oxygen plasma radiation, respectively, in the VUV-UV-VIS-NIR. Pseudodielectric constants (a) $\left\langle\varepsilon_{1}\right\rangle$ and (b) $\left\langle\varepsilon_{2}\right\rangle$.
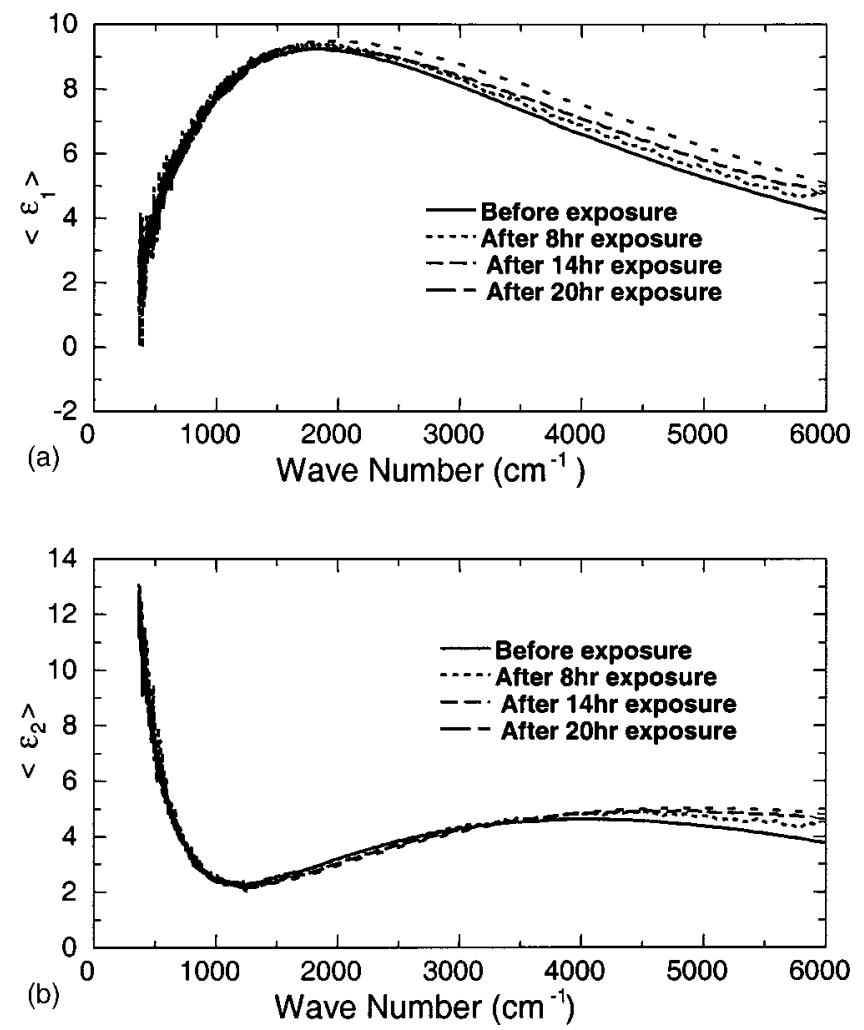

FIG. 7. Comparison of spectroscopic ellipsometric raw data obtained from a previous $\mathrm{ZnSe}$ sample in Fig. 1 before and after 8, 14, and $20 \mathrm{~h}$ of oxygen plasma radiation, respectively, in the MIR. Pseudodielectric constants (a) $\left\langle\varepsilon_{1}\right\rangle$ and $(\mathrm{b})\left\langle\varepsilon_{2}\right\rangle$.

spectively. Like the $\Psi$ and $\Delta$ data, the pseudodielectric function includes the effects of roughness, oxidation, and finite film thickness. Note that the VUV data $(4.5-8.5 \mathrm{eV})$ were taken for only two cases: pristine and $20 \mathrm{~h}$ of oxygen plasma exposed ZnSe films. From Figs. 6(a) and 6(b), we see large peak shifts and amplitude changes. Obviously, shifts versus exposure time are fairly consistent. Below $\sim 4 \mathrm{eV}$, interference peaks shifted toward higher photon energies with oxygen plasma exposure, indicating film thinning; while above that region, where interband transitions dominate, peaks decreased in both amplitude and number (the two peaks around $4 \mathrm{eV}$ merging together), with no apparent trend set in terms of peak positions. Recall previous simulations in Figs. 4 and 5 where overlayer effects, including roughness and oxides, reduce $\varepsilon_{2}$ magnitude but shift peak positions only slightly. We suspect that roughness is so large that the EMA may no longer be valid at short wavelengths. In the middle IR region, however, as shown in Fig. 7 (data at $75^{\circ}$ are shown), no significant changes are seen over the entire region, except for the "tail" at higher energies, which is mainly due to layer thinning during exposure (discussed below).

Again, the HJ model was used to fit film optical constants after $20 \mathrm{~h}$ of oxygen plasma exposure over the entire spectral range available. The optical model employed was similar to the previous one except that thickness nonuniformity was included in place of surface roughness in the optical model. Surface roughness was "neglected" from the model due to 
strong correlations between roughness layer thickness and $\mathrm{ZnSe}$ film optical constants. We suspect that after $20 \mathrm{~h}$ of plasma exposure, an EMA layer was no longer valid for roughness representation due to a considerable increase in surface roughness. Visual evidence is provided as we compare $\left\langle\varepsilon_{2}\right\rangle$ decreases for the interband transition peaks in Figs. 4 and 6 . A significantly larger decrease is observed in Fig. 6 than what is found in Fig. 4 due to a $3 \mathrm{~nm}$ roughness, indicating that the $20 \mathrm{~h}$ plasma-treated films are a lot rougher than just $3 \mathrm{~nm}$. In addition to these indicators in $\langle\varepsilon\rangle$ of increased roughness, depolarization effects ${ }^{61}$ were found from the ellipsometric spectra as well, due to thickness nonuniformity, which is a better optical model for dealing with larger scale surface roughness. In this case, microscopic roughness was not explicitly modeled, but film thickness nonuniformity was. The exposed film (together with surface roughness) was represented by a HJ model layer, and thickness nonuniformity was also a fit parameter in the model. The film optical constants for oxygen plasma exposed samples thus are not directly corrected for surface roughness and oxides, rather are approximated in the optical model by non-uniformity. Figures $8(\mathrm{a})-8(\mathrm{c})$ are the best-fit results after $20 \mathrm{~h}$ oxygen plasma exposure in the UV-VIS-NIR, VUV, and middle IR regions, respectively, in terms of the pseudodielectric function $\left\langle\varepsilon_{2}\right\rangle$ (MSE $\left.\approx 2.24\right)$. As seen, fits are good except in the VUV spectral range, especially above $6 \mathrm{eV}$. Adding another oscillator to the HJ model did not help. Neither did replacing the HJ layer with a graded index model (based on the assumption that $\mathrm{ZnSe}$ films became nonuniform in depth after oxygen plasma exposure). Thickness nonuniformity in the model helped slightly. The problem with VUV fits is likely due to general lateral inhomogeneity in the top (exposed) surface due to plasma exposure. However, fits in the longwavelength regions are reasonably good, and the resulting optical constants can be used for optical modeling of infrared electrochromic device performance.

The as-determined optical constants of the exposed $\mathrm{ZnSe}$ films are shown in Figs. 9(a) and 9(b), along with those of the pristine films. As overlayer (roughness and oxides) effects alone could not make such a huge difference (other than decreasing peak amplitudes), changes in film optical constants are, therefore, found to be substantial in shorter wavelengths. However, for the middle IR spectral range, which is of utmost interest for device operation $(2-35 \mu \mathrm{m})$, the differences are much smaller.

In this experiment we used three separate spectral ellipsometers over different spectral ranges, so the locations of the beam on the sample changed. Because of film nonuniformity after oxygen plasma exposure, a "multisample" analysis $^{62}$ was used for the data from the three instruments. That is, instead of three samples, the data from one sample but three (overlapping) spectral ranges were used. The $\mathrm{ZnSe}$ films were found to get thinner by about $20 \%$ (decreased from $\sim 98$ to $\sim 78 \mathrm{~nm}$ for the sample shown in Figs. 2 and 8 ) after $20 \mathrm{~h}$ oxygen plasma exposure, roughly equivalent to $\sim 16$ years in LEO. Thickness nonuniformity was determined to be $\sim 17 \%$, a considerable increase compared with before
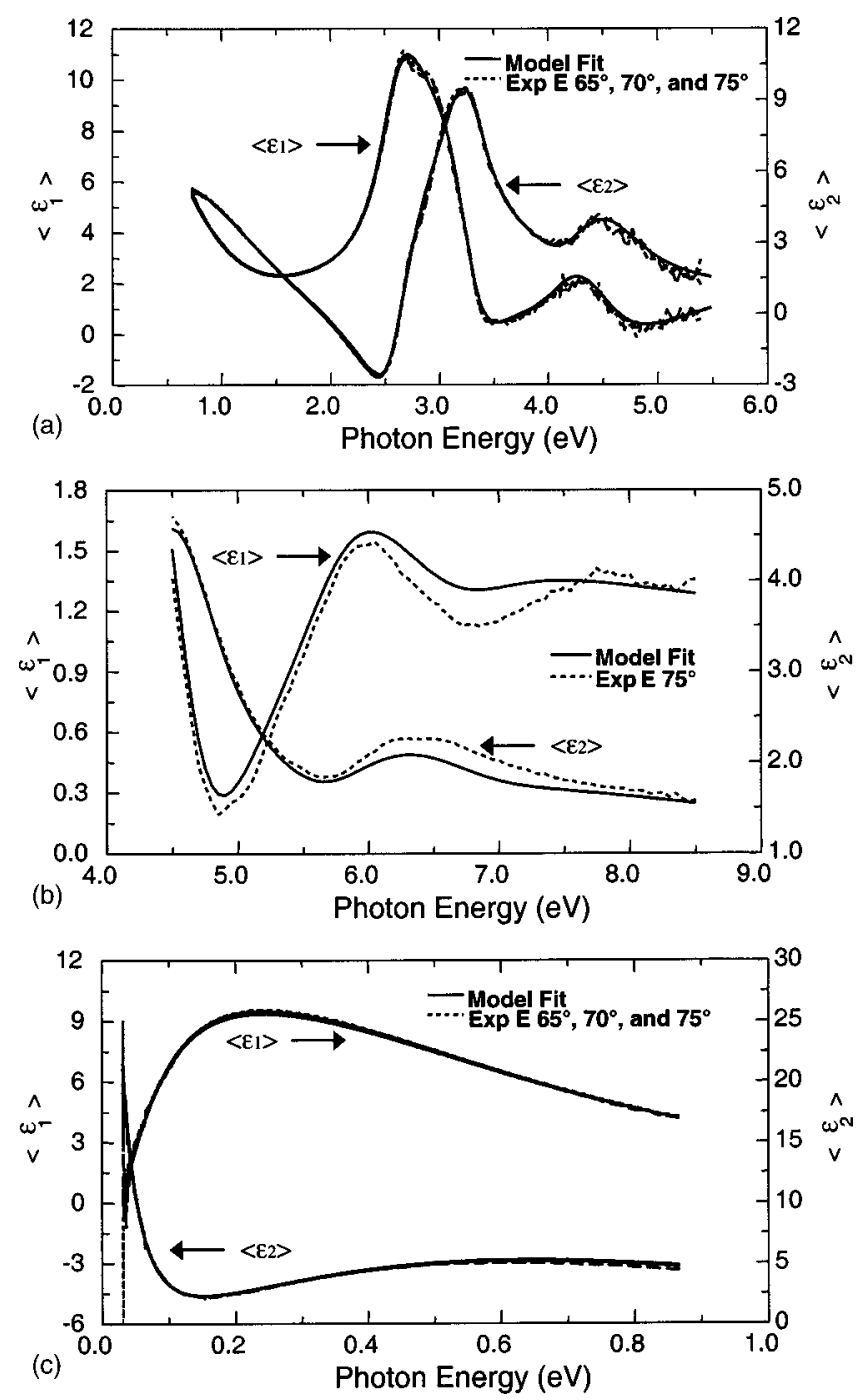

FIG. 8. VUV-UV-VIS-NIR-MIR raw data obtained from a previous ZnSe sample in Fig. 1 after $20 \mathrm{~h}$ of oxygen plasma exposure, combined with the best HJ model fits in (a) the UV-VIS-NIR, (b) the VUV, and (c) the MIR.

irradiation, where the nonuniformity was negligible.

Our proposed application is IR protective antireflection coatings, thus increases in the optical extinction coefficient are a potential problem. To see if the $\mathrm{ZnSe}$ films will be transparent enough for optical coatings after oxygen plasma exposure, a transmittance calculation was made based on the determined optical constants, assuming the $\mathrm{ZnSe}$ film to be $0.5 \mu \mathrm{m}$ thick. The results are listed in Table I at a few selected wavelengths. Obviously, the increases in $k$ are too small to cause meaningful intensity loss, meaning the $\mathrm{ZnSe}$ films are sufficiently transparent even after $20 \mathrm{~h}$ of oxygen plasma exposure. Device performance simulations are addressed in Sec. IV C below.

\section{B. EDX}

To study chemical changes on the $\mathrm{ZnSe}$ sample surfaces, energy dispersive $\mathrm{x}$-ray spectroscopy (EDX) was used to ex- 

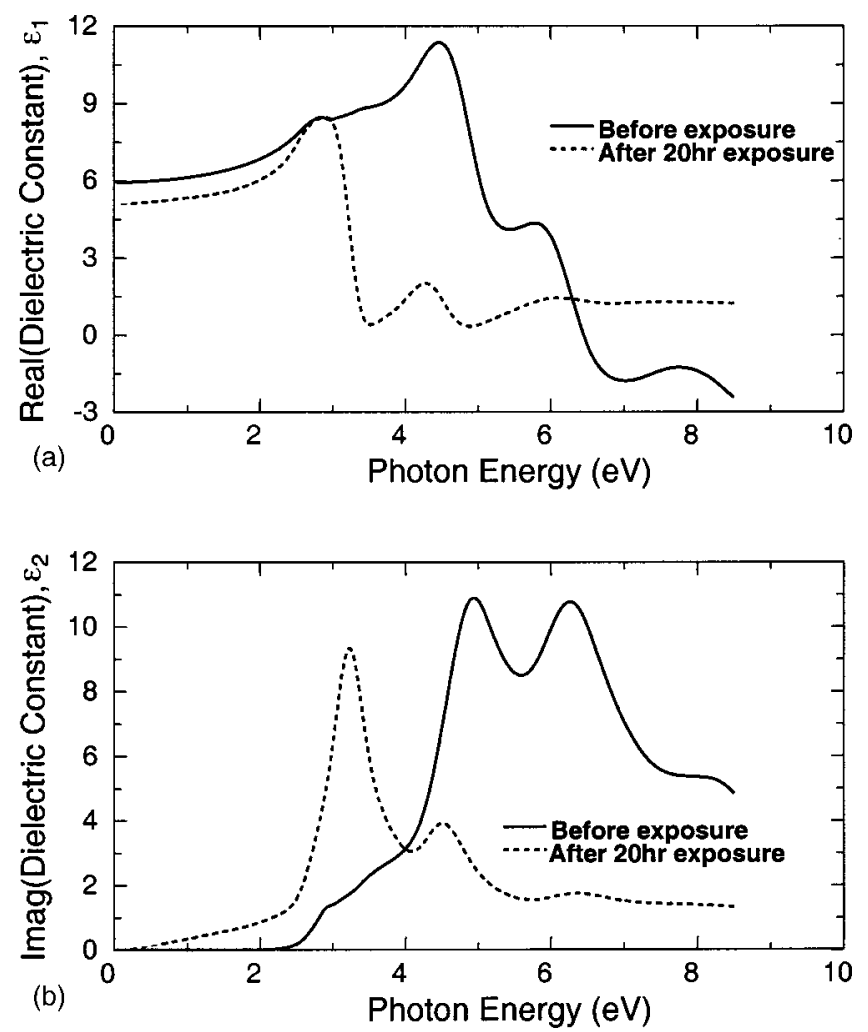

FIG. 9. Comparison of film optical constants before and after $20 \mathrm{~h}$ of oxygen plasma exposure in the VUV-UV-VIS-NIR-MIR spectral range. Dielectric optical constants (a) $\varepsilon_{1}$ and (b) $\varepsilon_{2}$.

amine the surfaces both before and after oxygen plasma exposure. The only difference was that a tiny oxygen peak emerged after oxygen plasma exposure. Normally, this is a sign of an oxide formation upon irradiation, which could be zinc oxide $(\mathrm{ZnO})$, zinc peroxide $\left(\mathrm{ZnO}_{2}\right)$, or a related compound. However, we should have been able to see corresponding new peaks (predicted to be at $\sim 500 \mathrm{~cm}^{-1}$ for $\mathrm{ZnO}$ and $\sim 350 \mathrm{~cm}^{-1}$ for $\mathrm{ZnO}_{2}$, for instance) in the $\mathrm{IR},{ }^{63}$ but did not. One possible explanation is that $\mathrm{ZnSe}$ thin films indeed got thinner due to oxygen plasma erosion; meanwhile, oxygen atoms may have been (physically) trapped into $\mathrm{ZnSe}$ lattice structures, taking on a form of either $\mathrm{O}_{2}$ or $\mathrm{O}$ (not as likely because of its active nature). Since no chemical bonding was formed between trapped oxygen atoms and the $\mathrm{ZnSe}$ lattice, no characteristic peaks associated with oxides were

TABLE I. Calculations on ZnSe film transmittance after $20 \mathrm{~h}$ of AO exposure at a few selected wavelengths.

\begin{tabular}{cccr}
\hline \hline $\begin{array}{c}\text { Wavelength, } \\
\lambda(\mu \mathrm{m})\end{array}$ & $\begin{array}{c}\text { Extinction } \\
\text { coefficient, } K\end{array}$ & $\begin{array}{c}\text { Absorption coefficient, } \\
\alpha(1 / \mu \mathrm{m})\end{array}$ & $I / I_{0} \mathrm{a}^{\mathrm{a}}$ \\
\hline 2.0 & 0.0384 & 0.240 & 0.887 \\
2.5 & 0.0282 & 0.142 & 0.932 \\
5.0 & 0.0115 & 0.0289 & 0.986 \\
10.0 & 0.00532 & 0.00669 & 0.997 \\
20.0 & 0.00260 & 0.00163 & 0.999 \\
30.0 & 0.00173 & 0.000722 & $\sim 1.000$ \\
\hline \hline
\end{tabular}

${ }^{\mathrm{a}} I / I_{0}=\exp (-\alpha \times 0.5)$, assuming the $\mathrm{ZnSe}$ film is $0.5 \mu \mathrm{m}$ thick.

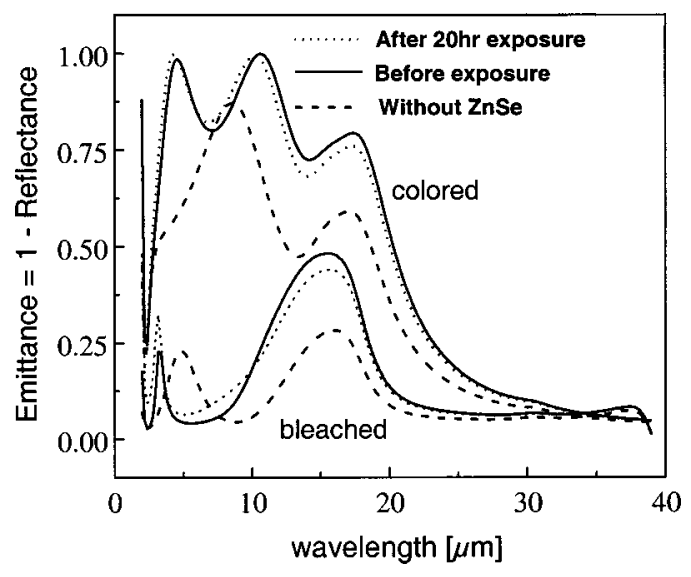

FIG. 10. Simulated thermal emittance spectra for an electrochromic device, with and without a $500 \mathrm{~nm} \mathrm{ZnSe}$ layer on top of the Al top electrode grid.

observed in the IR spectra. Increased optical absorption is seen below the band edge due to disturbances to the $\mathrm{ZnSe}$ lattice structure. These energy shifts of the "band gap" are shown in Fig. 9. Keep in mind that film optical constants after plasma exposure are due to the $\mathrm{ZnSe}$ film plus whatever overlayers (including roughness and/or oxides) are on top. Therefore the large differences in spectra observed in Fig. 9 are not due to changes in $\mathrm{ZnSe}$ itself; rather to changes in film plus overlayers. In the infrared region, energy shifts are not detected because the extinction coefficient $(k)$ of $\mathrm{ZnSe}$ is quite small. Hence a small shift in the band-gap energy does not significantly affect the infrared spectra.

\section{Theoretical electrochromic device performance}

Theoretical device performance was evaluated based on previous experimental device results ${ }^{33,34}$ and the optical data on degraded $\mathrm{ZnSe}$ layers presented in this article. Details of this performance study are being published elsewhere. ${ }^{64}$ Briefly, the ZnSe layer thickness was optimized for each temperature examined in order to obtain the best electrochromic emissivity modulation. The $\mathrm{ZnSe}$ layer produces two effects: (i) it serves as a protection layer for $\mathrm{WO}_{3}$, and (ii) it improves the optical device performance in the IR spectral region due to optical frequency impedence matching. An example for the emissivity modulation using a $500 \mathrm{~nm}$ thick ZnSe layer is given in Fig. 10. As is clearly seen the emissivity modulation is considerably higher with than without the $\mathrm{ZnSe}$ layer. The device emissivity was calculated by integration over the $300 \mathrm{~K}$ blackbody spectra. The oxygen plasma treatment of the ZnSe top layer was found to only slightly decrease the $300 \mathrm{~K}$ emissivity modulation, and modulation ratio of the electrochromic device, as shown in Fig. 10. Here, the optical constants of $\mathrm{ZnSe}$, determined in this study from $\mathrm{ZnSe}$ single layers before and after oxygen plasma exposure, were used for the simulation. For details on these electrochromic devices, along with their emittance modulation performance, see Refs. 33, 34, and 64. 


\section{CONCLUSIONS}

The Herzinger-Johs model was successfully used to obtain excellent fits over the entire spectral range available, starting from the VUV up to the middle IR (146 nm to 40 $\mu \mathrm{m})$. Six critical points were observed, corresponding to $E_{0}$, $E_{0}+\Delta E_{0}, E_{1}, E_{1}+\Delta E_{1} E_{2}$, and $E_{0}^{\prime}$, at $2.79 \pm 0.01,3.54$ $\pm 0.06,4.2 \pm 0.3,5.0 \pm 0.5,6.29 \pm 0.07$, and $8.1 \pm 0.3 \mathrm{eV}$, respectively, with the latter two being reported experimentally for the first time.

Drastic changes were detected upon oxygen plasma irradiation in the VUV-UV-VIS-NIR region, while few were seen in the middle IR, suggesting that few chemical changes occurred under plasma exposure. The ZnSe thin films got thinner by about $20 \%$ (decreased from $\sim 98$ to $\sim 78 \mathrm{~nm}$ for the sample shown in Figs. 2 and 8) after $20 \mathrm{~h}$ of AO exposure, an equivalent of $\sim 16$ years in LEO; meanwhile, films became rather nonuniform $(\sim 17 \%)$ in terms of thickness.

EDX data after oxygen plasma exposure showed an oxygen peak. However, IR SE obtained previously showed no oxide characteristic peaks (either zinc oxide or zinc peroxide) in the middle IR spectral range. One possible explanation is that oxygen atoms became trapped in the $\mathrm{ZnSe}$ lattice structure and took the form of $\mathrm{O}_{2}$ (most likely). No oxide characteristic peaks were observed in the IR spectra, therefore we conclude that there was no detectable chemical bonding between trapped oxygen atoms and the $\mathrm{ZnSe}$ lattice. Oxygen incorporation, however, could induce changes, especially in peak amplitudes, and somewhat in positions. As our proposed application is for infrared coatings, it is therefore enough to know that there are relatively few changes in the ZnSe film optical constants even after exposure corresponding to the equivalent of 16 years in orbit in the LEO environment.

Theoretical infrared electrochromic device performance was evaluated based on previous experimental device results, along with optical data obtained from the present experiments. A ZnSe layer was found to improve the device performance significantly. For $300 \mathrm{~K}$ applications, the ZnSe surface layer acted sufficiently as a protective layer and improved the infrared optical device performance, with little degradation due to oxygen exposure.

\section{ACKNOWLEDGMENTS}

This work is supported by the NASA Glenn Research Center, Grant No. NAG3-2219 and the National Science Foundation Contract No. NSF II-9901510-EE-UNL. The authors would like to thank James N. Hilfiker, Corey Bungay, Tom Tiwald, and Daniel W. Thompson for enlightening discussions and suggestions.

${ }^{1}$ S. T. Lakshmikumar and A. C. Rastogi, Thin Solid Films 259, 150 (1995).

${ }^{2}$ D. A. Ross, in Optoelectronic Devices and Optical Imaging Techniques (Macmillan, London, 1979).

${ }^{3}$ A. Rogers, in Essentials of Optoelectronics (Chapman and Hall, London, 1997).

${ }^{4} \mathrm{P}$. Bhattacharya, in Semiconductor Optoelectronic Devices (Prentice Hall, New Jersey, 1997).

${ }^{5}$ E. Masetti, M. Montecchi, and M. P. da Silva, Thin Solid Films 234, 557 (1993).
${ }^{6}$ A. Deneuville, D. Tanner, and P. H. Holloway, Phys. Rev. B 43, 6544 (1991).

${ }^{7}$ P. Meredith, G. S. Buller, and A. C. Walker, Appl. Opt. 32, 5619 (1993). ${ }^{8}$ R. M. Bueno, J. F. Trigo, J. M. Martinez-Duart, E. Elizalde, and J. M. Sanz, J. Vac. Sci. Technol. A 13, 2378 (1995).

${ }^{9}$ M. E. Sherif, F. S. Terra, and S. A. Khodier, J. Mater. Sci. 7, 391 (1996).

${ }^{10}$ R. C. Tu, Y. K. Su, C. F. Li, Y. S. Huang, S. T. Chou, W. H. Lan, S. L. Tu, and H. Chang, J. Appl. Phys. 83, 1664 (1998).

${ }^{11}$ S. Adachi and T. Taguchi, Phys. Rev. B 43, 9569 (1991).

${ }^{12}$ Y. D. Kim, S. L. Cooper, M. V. Klein, and B. T. Jonker, Appl. Phys. Lett. 62, 2387 (1993).

${ }^{13}$ J. C. Jans, J. Petruzzello, J. M. Gaines, and D. J. Olego, Proc. SPIE 1985, 260 (1993).

${ }^{14}$ R. Dahmani, L. Salamanca-Riba, N. V. Nguyen, D. Chandler-Horowitz, and B. T. Jonker, J. Appl. Phys. 76, 514 (1994).

${ }^{15}$ K. Kato, F. Akinaga, T. Kamai, and M. Wada, J. Cryst. Growth 138, 373 (1994).

${ }^{16}$ C. C. Kim and S. Sivananthan, Phys. Rev. B 53, 1475 (1996).

${ }^{17}$ J. Lee, R. W. Collins, A. R. Heyd, F. Flack, and N. Samarth, Appl. Phys. Lett. 69, 2273 (1996)

${ }^{18}$ M. S. Koo, T. J. Kim, M. S. Lee, M. S. Oh, Y. D. Kim, S. D. Yoo, D. E. Aspnes, and B. T. Jonker, Appl. Phys. Lett. 77, 3364 (2000).

${ }^{19}$ Proceedings of the Sixth International Symposium on Materials in a Space Environment, edited by T.-D. Guyenne (ESTEC, Noordwijk, The Netherlands, 1994).

${ }^{20}$ Proceedings of the Seventh International Symposium on Materials in a Space Environment, edited by T.-D. Guyenne (ESA, The Netherlands, 1997).

${ }^{21}$ Proceedings of the Eighth International Symposium on Materials in a Space Environment, Fifth International Conference on Protection of Materials and Structures from the LEO Space Environment (Centre National D'tetudes Spatiales, Toulouse, France, 2000).

${ }^{22}$ Materials Degradation in Low Earth Orbit (LEO), edited by V. Srinivasan and B. A. Banks (Minerals, Metals \& Materials Society, Warrendals, Pennsylvania, 1990).

${ }^{23}$ Protection of Materials and Structures from the Low Earth Orbit Space Environment, edited by J. I. Kleiman and R. C. Tennyson (Kluwer, The Netherlands, 1999).

${ }^{24}$ S. L. Koontz, K. Albyn and L. J. Leger, J. Spacecr. Rockets 28, 315 (1991).

${ }^{25}$ S. Packirisamy, D. Schwam, and M. H. Litt, J. Mater. Sci. 30, 308 (1995).

${ }^{26}$ B. A. Banks, K. K. de Groh, E. Baney-Barton, E. A. Sechkar, P. K. Hunt, A. Willoughby, M. Bemer, S. Hope, J. Koo, C. Kaminski, and E. Yougstrom, NASA Technical Memorandum 209180, 1999.

${ }^{27}$ Joyce A. Dever, NASA Technical Memorandum 103711, 1991.

${ }^{28}$ B. A. Banks, K. K. de Groh, S. K. Rutledge, and F. J. Difilippo, NASA Technical Memorandum 107209, 1996.

${ }^{29}$ D. G. Zimcik and C. R. Maag, J. Spacecr. Rockets 25, 162 (1988).

${ }^{30}$ M. R. Reddy, J. Mater. Sci. 30, 281 (1995).

${ }^{31}$ S. L. Koontz, L. J. Leger, and J. T. Visentine, J. Spacecr. Rockets 32, 483 (1995).

${ }^{32}$ J. S. Hale, M. D. Vries, B. Dworak, and J. A. Woollam, Thin Solid Films 313-314, 205 (1998)

${ }^{33}$ E. B. Franke, C. L. Trimble, M. Schubert, J. A. Woollam, and J. S. Hale, Appl. Phys. Lett. 77, 930 (2000).

${ }^{34}$ E. B. Franke, C. L. Trimble, J. S. Hale, M. Schubert, and J. A. Woollam, J. Appl. Phys. 88, 5777 (2000).

${ }^{35}$ J. A. Woollam, B. Johs, C. M. Herzinger, J. Hilfiker, R. Synowicki, and C. L. Bungay, Proc. SPIE CR72, 3 (1999).

${ }^{36}$ B. Johs, J. A. Woollam, C. M. Herzinger, J. Hilfiker, R. Synowicki, and C. L. Bungay, Proc. SPIE CR72, 29 (1999).

${ }^{37}$ Proceedings of the Second International Conference on Spectroscopic Ellipsometry, edited by R. W. Collins, D. E. Aspnes, and E. A. Irene (Elsevier Science S. A., Switzerland, 1998), p. 1.

${ }^{38}$ D. E. Aspnes, in Handbook of Optical Constants of Solids, edited by E. D. Palik (Academic, New York, 1985), p. 89.

${ }^{39}$ J. C. Jans, Philips J. Res. 47, 347 (1993).

${ }^{40}$ R. M. A. Azzam and N. M. Bashara, Ellipsometry and Polarized Light (North-Holland, New York, 1977).

${ }^{41}$ J. N. Hilfiker, B. Singh, R. A. Synowicki, and C. L. Bungay, Proceedings of SPIE Microlithography 2000 Conference (in press). 
${ }^{42}$ D. E. Aspnes and A. A. Studna, Phys. Rev. B 27, 985 (1983).

${ }^{43}$ S. Adachi, Phys. Rev. B 38, 12345 (1988).

${ }^{44}$ S. Adachi, J. Appl. Phys. 66, 6030 (1989).

${ }^{45}$ A. R. Forouhi and I. Bloomer, Phys. Rev. B 38, 1865 (1988).

${ }^{46}$ W. A. McGahan, T. Makovicka, J. Hale, and J. A. Woollam, Thin Solid Films 253, 57 (1994).

${ }^{47}$ G. E. Jellison, Jr. and F. A. Modine, Appl. Phys. Lett. 69, 371 (1996).

${ }^{48}$ M. Erman, J. B. Theeten, P. Chambon, S. M. Kelso, and D. E. Aspnes, J. Appl. Phys. 56, 2664 (1984).

${ }^{49}$ H. D. Yao, P. G. Snyder, and J. A. Woollam, J. Appl. Phys. 70, 3261 (1991).

${ }^{50}$ C. C. Kim, J. W. Garland, H. Abad, and P. M. Raccah, Phys. Rev. B 45, 11749 (1992).

${ }^{51}$ C. C. Kim, J. W. Garland, and P. M. Raccah, Phys. Rev. B 47, 1876 (1993).

${ }^{52}$ C. M. Herzinger and B. Johs, US Patent No. 5,796,983 (1998).

${ }^{53}$ WVASE32 ${ }^{\circledR}$ Software manual, J. A. Woollam Co., Inc. (unpublished).
${ }^{54}$ B. Johs, C. M. Herzinger, J. H. Dinan, A. Cornfeld, and J. D. Benson, Thin Solid Films 313-314, 137 (1998).

${ }^{55}$ D. E. Aspnes, J. B. Theeten, and F. Hottier, Phys. Rev. B 20, 3292 (1979). ${ }^{56}$ M. Cardona, J. Appl. Phys. 32, 2151 (1961).

${ }^{57}$ M. Aven et al., J. Appl. Phys. 32, 2261 (1961).

${ }^{58}$ F. H. Pollak, in II-VI Semiconducting Compounds, edited by D. G. Thomas (Benjamin, New York, 1967), p. 552.

${ }^{59}$ D. L. Greenaway and G. Harbeke, Optical Properties and Band Structure of Semiconductors (Pergamon, Oxford, 1968).

${ }^{60}$ D. E. Aspnes and A. A. Studna, Appl. Phys. Lett. 39, 316 (1981).

${ }^{61}$ G. E. Jellison, Jr. and J. W. McCamy, Appl. Phys. Lett. 61, 512 (1992).

${ }^{62}$ C. M. Herzinger, H. Yao, P. G. Snyder, F. G. Celii, Y.-C. Kao, B. Johs, and J. A. Woollam, J. Appl. Phys. 77, 4677 (1995).

${ }^{63}$ Handbook of Infrared and Raman Spectra of Inorganic Compounds and Organic Salts, edited by R. A. Nyquist and R. O. Kagel (Academic, San Diego, CA, 1997).

${ }^{64}$ E. Franke, H. Neumann, M. Schubert, C. L. Trimble, L. Yan, and J. A. Woollam, Surf. Coat. Technol. (in press). 